\title{
¿Ojo por ojo, diente por diente?: \\ Análisis de la modificación del artículo 920 del Código Civil.
}

\section{Raúl Ravina 1}

Con este trabajo académico, el doctor Raúl Ravina repasa los principales aspectos de la posesión y sus métodos de defensa. A continuación, el autor comenta las implicancias, ventajas y desventajas que ha traído consigo la reciente modificación del Código Civil en materia de defensa posesoria extrajudicial.

Abogado por la Pontificia Universidad Católica del Perú, Socio del Estudio Grau SCRL, es actualmente profesor en la Facultad de Derecho en la Universidad del Pacifico y en la de la Universidad Peruana de Ciencias Aplicadas y ha sido profesor en la Facultad de Derecho de la Pontificia Universidad Católica del Perú.

** Quiero agradecer muy especialmente a Denisse Figueroa D'Ugard, Antonella Gutiérrez Rosales, y Nicole Nalvarte Atencia, alumnas de la Facultad de Derecho de la Universidad del Pacifico, quienes han participado con esmero en la preparación del presente trabajo. Las tres fueron excelentes alumnas del curso de Derechos Reales de la Facultad del Pacifico y han aportado con sus conocimientos e ímpetu en la preparación de este trabajo. Les auguro a ellas el mejor futuro profesional. 
¿Ojo por ojo, diente por diente?:

Análisis de la modificación del artículo 920 del Código Civil.

"podemos repeler con las armas al que viene con armas; mas esto inmediatamente, no después de un intervalo, con tal que sepamos que no solamente está permitido resistir, para no ser echado, sino que el que hubiere sido echado eche al mismo, no después de un intervalo, sino inmediatamente"

Según Ulpiano, Digesto, L. XLIII, t. XLI

El 12 de julio del presente año, se publicó la Ley No 30230 que, entre otros temas, modificó el artículo $920^{\circ}$ del Código Civil, referido a la defensa posesoria. El presente trabajo tiene por finalidad analizar los alcances de la modificación y la conveniencia de la misma.

\section{Heterocomposición y autotutela.-}

Desde comienzos de la humanidad, se han presentado conflictos entre los seres humanos, por razones de sobrevivencia, por una ofensa, por el derecho a tener algún bien o por algún incumplimiento, la vida en sociedad determina que se produzcan diferencias entre las personas, que tienen que ser resueltas. Es así que, en un primer momento, como sostiene Monroy $^{2}$, la "acción directa" se perfila como la primera solución a los conflictos de intereses en la evolución histórica de la humanidad, en la que "el animal humano resuelve en forma inmediata, práctica e instantánea sus conflictos intersubjetivos teniendo como instrumento exclusivo el uso de la fuerza" es decir, "es la prescindencia de todo método razonable para solucionar un conflicto de intereses".

En ese sentido, el mismo autor ${ }^{3}$ hace referencia a un ejemplo sencillo pero ilustrativo para entender la forma en que se resolvían los conflictos interpersonales al inicio de la

2 Monroy Gálvez, Juan, En: "Teoría General del Proceso", Palestra Editores, Lima 2007, pp. $39-40$.

3 Monroy Gálvez, Juan, En "Teoría General del Proceso", Palestra Editores, Lima 2007, p. 39. 
historia del ser humano: el escenario se centra en el Paleolítico inferior en el que se produce una disputa entre dos hombres primitivos, originada en atención a que uno le ha arrebatado la lanza (su instrumento de supervivencia) al otro; así, luego del despojo, el perjudicado busca recuperar la lanza a la fuerza, por tanto la manera de solucionar el conflicto de intereses originado en la posesión de la lanza es la confrontación física directa entre los protagonistas con la probable desaparición o inutilización de ambos contendientes. En la misma línea se pronuncian Alzamora Valdez ${ }^{4}$ y Couture ${ }^{5}$.

Sin embargo, esta forma de resolución de conflictos hubiese podido terminar en la autodestrucción de nuestra especie, por ello, los seres humanos deciden ponerse de acuerdo en respetar algunas reglas básicas de respeto mutuo que, entre otras obligaciones, impone poner en manos de un tercero (el Estado) la resolución de sus disputas, eliminándose la acción directa. Así, lo señala Monroy ${ }^{6}$, las situaciones que en los estadios primitivos de la civilización fueron resueltas directamente utilizando la fuerza, y con el tiempo se fueron autorregulando por cada cultura, postulándose inicialmente la intervención de un tercero quien, al evitar la agresión directa de los interesados, proponía además una solución al conflicto. ${ }^{7}$

Esta forma de resolver conflictos se conoce como heterocomposición y es la forma más civilizada en que los seres humanos en sociedad resuelven los conflictos que no han podido resolver directamente de forma civilizada ${ }^{8}$. Al respecto, Reggiardo ${ }^{9}$ señala que

$4 \quad$ "En las sociedades primitivas-históricas o actuales- los hombres apelan a la fuerza para defender sus derechos. Cada cual califica su pretensión, elige los medios para poner término a la amenaza y para vengar el agravio; es, de este modo, juez y parte en los conflictos que le atañen". Alzamora Valdez, Mario, Derecho Procesal Civil-Teoría General del Proceso, Lima, Tipografía Peruana. 1967, p. 1.

$5 \quad$ "El hombre primitivo, no sólo primitivo en la edad histórica sino también primitivo en la formación de sus sentimientos e impulsos morales, la reacción contra la injusticia parece bajo la forma de venganza. El primer impulso del alma rudimentaria es la justicia por propia mano. Sólo a expensas de grandes esfuerzos históricos ha sido posible sustituir en el alma humana la idea de la justicia por mano propia por la idea de justicia a cargo de la autoridad". Couture, Eduardo J., Introducción al Estudio del Proceso Civil, Buenos Aires. De Palma. 1978. p. 16-17.

6 Monroy Gálvez, Juan, "Conceptos elementales de Proceso Civil", En: "Revista del Foro", Colegio de Abogados de Lima, Año LXXXI, N 1, Lima, 1993, p. 75.

7 "De un caos en que prevalecía la Ley del más fuerte se pasó a un orden jurídico en que prevalece el criterio de un sujeto imparcial sustituyéndose la acción directa frente al adversario por la acción dirigida hacia el Estado (...)". González Pérez, Jesús, El derecho a la tutela jurisdiccional, Madrid, Civitas, 1984, p. 20.

$8 \quad$ Método conocido como el de la Autocomposición que consiste en la resolución del conflicto a partir de un acuerdo entre las partes, en el que no medie coacción y/o coerción, por parte de los involucrados en el referido conflicto en atención a sus intereses 
este método se caracteriza porque las partes no solucionan el conflicto por sí mismas, sino que la labor corresponde a un tercero cuya decisión es de obligatorio cumplimiento para ellas ${ }^{10}$.

Frente a la heterocomposición, tenemos a la autotutela, respecto a la cual AlcaláZamora señala que, "expresa la natural reacción del sujeto lesionado en su interés, cuando el impulso de los contendientes en litigio, que al acudir a ella se dejan llevar por consideraciones egoístas, con prescindencia de toda idea de solidaridad social ${ }^{\prime \prime 11}$.

Respecto a la autotutela, Reggiardo comenta que la alta probabilidad de que se generen consecuencias nefastas a partir del actuar violento, llevó a que las sociedades busquen métodos donde un tercero intermedie para evitar la descomposición social, de ahí que la autotutela generalmente está prohibida por la ley y es permitida solo de manera excepcional. Por su parte, Véiscoi ${ }^{12}$ señala que "la autotutela se caracteriza por dos notas especiales: (i) la ausencia de un tercero distinto a las partes que pueda resolver el conflicto; y, (ii) la imposición de la decisión de una de las partes a la otra."

La existencia de la heterocomposición no elimina del todo la autotutela, de hecho, por excepción, nuestro ordenamiento admite algunos supuestos de autotutela que Reggiardo ${ }^{13}$, aplicando los criterios utilizados por Ovalle Favella ${ }^{14}$, los clasifica de la siguiente manera:

"(i) la respuesta a un ataque precedente, que es el caso de la legitima defensa (artículo 20.3 del Código Penal) o del derecho del poseedor a repelar razonablemente la fuerza que se emplee contra él y a recobrar el bien, sin intervalo de tiempo, si fuere desposeído (artículo 921 del Código

particulares, por lo que, estamos ante un mecanismo que depende de la decisión de los involucrados.

9 Reggiardo Saavedra, Mario, "Encuentros y desencuentros de la jurisdicción: sobre el diseño constitucional de la solución de conflictos". En: "Ius et veritas", Lima, 2013, p. 2021.

10 Asimismo, describe que a partir de quién resuelve el conflicto tenemos dos formas de heterocomposición: privada (como el arbitraje), en la que las partes escogen libremente la persona o personas que van a solucionar el conflicto; y pública, en la que un órgano del Estado es quien tiene el poder de solucionar el conflicto.

11 Alcalá-Alzamora Y Castillo, Niceto, Proceso, Autocomposición y defensa, 2da Ed., Universidad Nacional Autónoma de México, México, 1970, p. 30.

12 Véscovi, Enrique, Manual de derecho procesal: actualizado según el Código General del Proceso, $3^{\circ}$ Edición, Ediciones Idea, Montevideo, 1994, p. 9.

13 Reggiardo Saavedra, Mario, "Encuentros y desencuentros de la jurisdicción: sobre el diseño constitucional de la solución de conflictos". En: Ius et veritas, Lima, 2013, p. 1718.

14 Ovalle Favela, José, En "Teoría general del proceso", Tercera edición, Oxfrod University Press - Harla, México D.F., 1996, p. 11-14. 
Civil ${ }^{15}$; (ii) el derecho de retención del poseedor en los casos que debe ser reembolsado de mejoras (artículo 918 del Código Civil); (iii) el ejercicio de las facultades atribuidas al mando para hacer frente a situaciones de excepción, como es el caso de la obediencia jerárquica (artículo 20.9 del Código Penal); (iv) el ejercicio de la potestad de uno de los sujetos en conflicto, como son las facultades disciplinarias y sancionadoras, y; (v) la presión o coacción sobre la contraparte para lograr el prevalecimiento de los propios intereses, también conocida como medida conflictiva."

En ese sentido, Reggiardo, citando a Alcalá-Zamora, comenta que el referido autor considera que:

'(...) aquellas formas (de autotutela) no pueden estimarse antijurídicas puesto que las autoriza el ordenamiento jurídico, deben reputarse como ajurídicas desde el punto de vista del sujeto que las utiliza. Pone como ejemplo el caso de la legítima defensa. Cuando un hombre es agredido por otro, así este sea un eximio penalista, no evoca requisitos legales de la legítima defensa para acomodar a ellas su reacción. Repelerá el ataque como pueda y con lo queda. Será después el órgano jurisdiccional quien evalué si quien alega defensa legitima se excedió o no de los requisitos previstos por la ley ${ }^{16} . "$

Dado que el tema central de este artículo es la defensa extrajudicial de la posesión, haremos una comparación entre los dos supuestos admitidos de autotutela que conllevan una respuesta a un ataque previo: la legitima defensa (en materia penal) y la defensa extrajudicial de la posesión ${ }^{17}$. En ese sentido, para simplificar la comparación, presentamos el siguiente cuadro.

\begin{tabular}{|l|l|}
\hline \multicolumn{1}{|c|}{ Defensa extrajudicial de la posesión } & \multicolumn{1}{|c|}{ Legítima Defensa $^{18}$} \\
\hline $\begin{array}{l}\text { Despojo o intento de despojo: conducta } \\
\text { ilegitima destinada a privar de la posesión } \\
\text { al poseedor actual y tomarla para sí. }\end{array}$ & $\begin{array}{l}\text { Agresión ilegítima: conducta humana que } \\
\text { es actual (que la agresión sea inminente y } \\
\text { se siga desarrollando) y agrede a un bien } \\
\text { jurídico. }\end{array}$ \\
\hline
\end{tabular}

15 El artículo correcto es el 920 del Código Civil.

16 Reggiardo Saavedra, Mario, Encuentros y desencuentros de la jurisdicción: sobre el diseño constitucional de la solución de conflictos. En: Ius et veritas, Lima, 2013, p. 18.

17 Utilizaremos para estos efectos el texto recientemente derogado.

18 Villavicencio Terreros, Felipe, Derecho Penal: Parte General, Primera Edición, Grijley, Lima, 2006, p. 534-546. 


\begin{tabular}{|c|c|}
\hline $\begin{array}{lll}\text { ¿Cómo? Proporcional a los medios } \\
\text { utilizados en la agresión, sin exceder lo } \\
\text { necesario para evitar el despojo o } \\
\text { recuperar el bien. }\end{array}$ & $\begin{array}{l}\text { Necesidad de Defensa: "Solo los bienes del } \\
\text { agresor pueden ser afectados por la } \\
\text { defensa siempre que le sirvan para la } \\
\text { agresión". La referida defensa debe ser } \\
\text { necesaria y racional, es decir," (...) la } \\
\text { idónea para impedir o repeler la agresión". }\end{array}$ \\
\hline \multirow[t]{2}{*}{$\begin{array}{l}\text { ¿Cuándo? En la mínima unidad de tiempo } \\
\text { existente entre el ataque y la defensa. Ello } \\
\text { en atención a la dramática situación en la } \\
\text { que se encuentra. }\end{array}$} & $\begin{array}{l}\text { Falta de provocación suficiente: "El sujeto } \\
\text { que se defiende no debe haber provocado } \\
\text { la agresión". }\end{array}$ \\
\hline & $\begin{array}{l}\text { Elemento subjetivo: "La acción defensiva } \\
\text { debe responder a una voluntad de } \\
\text { defensa". }\end{array}$ \\
\hline
\end{tabular}

Como se puede apreciar, más allá de algunas particularidades, ambas instituciones coinciden en que i) se tratan de medidas excepcionales que sólo se permiten en tanto se cumplan todos los elementos de hecho que las normas que las autorizan exigen, ii) buscan evitar la consumación de un daño inminente, iii) debe haber concurrencia o inmediatez entre la agresión y la acción de autotutela, iv) la respuesta debe ser proporcional y no debe usarse como una oportunidad de infringir un daño desproporcionado al agresor, es decir, en ningún caso está legitimada la venganza.

Finalmente, debe entenderse que si nuestro ordenamiento admite estos supuesto excepcionales de autotutela lo hace porque considera que no existe otra alternativa de solución mejor, en el momento en que se realizan los hechos. Sin embargo, la regulación de su ejercicio demuestra que el legislador ha querido que estos mecanismos se mantengan como excepcionales.

\section{El derecho de posesión.-}

El artículo 896 del Código Civil define a la posesión como "el ejercicio de hecho de uno o más poderes inherentes a la propiedad", siguiendo con esto la teoría objetiva de la posesión de Rudolf Von Ihering.

La teoría objetiva de la posesión relativiza (pero no elimina) el "animus" (o elemento voluntario) para la existencia de la posesión. En ese sentido, la voluntad requerida para la posesión es solo una voluntad de poseer (animus possidendi) por lo que el comportamiento solo requerirá de un origen de voluntad y que no se trate de un acto 
ausente de voluntad. Además, el "animus"sólo será identificable "incorporado" en el comportamiento.

En cambio, la teoría subjetiva de la posesión de Friedrich Karl Von Savigny (acogida en países como Argentina), considera indispensable, para que una situación sea considerada como posesoria, que la conducta venga acompañada de la "Intención de conducirse como propietario" o "animus domini" como elemento constitutivo de la posesión, y en ese sentido, no admite la condición posesoria de terceros como el arrendatario, comodatario o depositario (que para la teoría objetiva podrían ser poseedores inmediatos), pues ninguno desea dejar de reconocer la propiedad del dueño, sino que "detentan" el bien con el consentimiento del verdadero propietario.

En palabras simples, de acuerdo con la teoría objetiva de la posesión, que nuestro Código Civil acoge, será poseedor aquel que se comporte respecto a un bien como razonablemente se comportaría un propietario. La posesión surge de la conducta propia así como de su impacto en los terceros, de manera que el poseedor actúa sobre el bien como lo haría el propietario o copropietario legítimo o titular de algún derecho patrimonial sobre el bien ${ }^{19}$. Respecto a los terceros, la posesión debe tener un carácter aparente, debe ser pública e identificable socialmente, pues el poseedor, para ser tal, debe ser percibido como si fuera el propietario, aunque en la práctica no tendrá que serlo ${ }^{20}$.

En ese sentido, debe distinguirse el derecho a la posesión del derecho de posesión. El derecho a la posesión implica la legitimidad para poseer pero no necesariamente su ejercicio efectivo, es ese, por ejemplo, el caso de un propietario que, está legitimado para poseer (derecho a la posesión) y ha sido privado de su posesión efectiva. En cambio, un usurpador, si bien carece del derecho a la posesión por falta de legitimidad, ejerce la posesión efectiva del bien (derecho de posesión)

19 Cabe la posibilidad que un poseedor ejerza la posesión en condiciones distintas a las que lo haría un propietario. Es el caso de aquel que posee en razón de un derecho de servidumbre (cuente o no con este título) en este caso, el comportamiento requerido será distinto al que realizaría un poseedor a título de propietario. Por ejemplo, respecto a un predio agrícola, es diferente el comportamiento posesorio que realiza el propietario o el usufructuario del predio (que en la mayoría de casos implicará la siembra, cultivo y cuidado general del terreno) al comportamiento del vecino que ejerza una servidumbre de paso sobre el predio agrícola (que se expresará ejerciendo el paso por este predio)

Si bien la posesión es la "exteriorización" o ejercicio de hecho de los atributos de la propiedad y la protección de la posesión busca otorgar una defensa indirecta de la propiedad (porque posesión y propiedad muchas veces coinciden) no es necesario que el poseedor ostente la propiedad del bien ni ningún derecho menor que legitime su posesión. 
El derecho de posesión es una de las instituciones más importantes de los derechos reales $y$, en consecuencia, el sistema legal otorga al poseedor una serie de protecciones especiales de las que no gozan otros titulares de derechos. En efecto, el poseedor, más allá de que ejerza la posesión de forma legítima o ilegítima, tiene derecho a los frutos del bien ${ }^{21}$, al pago de las mejoras necesarias y útiles que realice en el bien y a retirar las de recreo (siempre que no se deteriore el bien) a la prescripción adquisitiva de dominio y, en especial, a la defensa posesoria.

En cuanto a la defensa de la posesión, nuestro sistema legal establece dos mecanismos especiales de protección posesoria, la defensa extrajudicial de la posesión y los interdictos de retener y recobrar ${ }^{22}$. En ambos casos, el legislador ha querido otorgar al poseedor de mecanismos muy expeditivos para la conservación y recuperación de la posesión ${ }^{23}$.

\section{La importancia de la defensa de la posesión}

El tema de la defensa de la posesión suele generar inquietud y preguntas como ¿Por qué se debe defender el derecho de posesión? ¿Cuál es el objetivo de defender a quien aparenta ser propietario, aun cuando en algunos casos no lo es? ¿Qué sucede si, efectivamente, no es propietario? ¿Debe protegerse al poseedor incluso contra el legítimo propietario?

Al respecto, cabe analizar cuál es la justificación por la cual se protege la posesión a pesar de ser una institución que se basa en la apariencia y que, por lo tanto, puede entrar en conflicto con otros derechos de gran importancia como el derecho de propiedad.

El artículo 912 del Código Civil establece que se presume que el poseedor es propietario, en se sentido, la protección de la posesión se basa en la protección de la

\footnotetext{
21 Con excepción del poseedor ilegitimo de mala fe.

22 El interdicto de retener protege al poseedor de perturbaciones a su posesión, el interdicto de recobrar protege al poseedor que ha sido privado de su posesión a partir de un despojo.

23 En el caso de los interdictos, la defensa judicial de la posesión se tramita en una vía procesal sumarísima, lo que busca que el proceso sea bastante más corto que un proceso de conocimiento. Sin embargo, si bien u proceso de interdicto de recobrar o retener debería tomar unos 12 meses, en la práctica, estos procesos toman en promedio 36 meses. Por su parte, la defensa extrajudicial o defensa directa de la posesión otorga al poseedor el derecho a defender su posesión de manera inmediata y evitar ser despojado o recuperar la posesión del bien.
} 
Civil.

propiedad. Y como señala Antonio Hernández Gil" ${ }^{24}$, "la tutela de la posesión descansa en razones de seguridad jurídica".

El autor explica que el problema se encuentra cuando la apariencia no coincide con la realidad. Este es el caso de los poseedores ilegítimos, aquellos que ejercen la posesión sin un título válido que los respalde ${ }^{25}$.

Por su parte, Mejorada Chauca ${ }^{26}$, citando a Ihering, comenta que "la posesión se configura como un sustituto de la prueba de la propiedad ante la dificultad inevitable que significa acreditar el domino en cada momento". También señala que "Si los propietarios tuvieran que probar su derecho cada vez que interactúan, se generarían una serie de complicaciones prácticas. Todo el tiempo los dueños tendrían que cargar con sus títulos de propiedad desplegando un enorme esfuerzo probatorio (...)."

Finalmente, Jiménez Vargas-Machuca ${ }^{27}$ comenta "Esta presunción llega con lógica y naturalidad, por cuanto la posesión es visible, casi palpable; se presenta a la vista, pues deriva de la sola apariencia, de la normalidad de su comportamiento. En síntesis, la posesión cumple con una función que se basa en la apariencia y en la normalidad."

Queda claro que la posesión es una exteriorización de la propiedad, una suerte de "cara de la propiedad" y por ello, alivia la carga de los propietarios de probar su derecho y sirve como una buena guía para la identificación del dueño de cierto bien. En la misma línea de los autores anteriormente citados, la presunción permite aliviar la carga probatoria de la propiedad a partir de la apariencia que la posesión conlleva.

En consecuencia, la protección posesoria se basa finalmente en la protección a la propiedad, aunque, en algunos casos, posesión y propiedad no coincidirán e incluso podrían entrar en conflicto. Por ello, es importante entender la relación que existe entre los mecanismos de protección posesoria y los de protección de la propiedad, en

24 Hernández Gil, Antonio, "La posesión como fenómeno social e institución jurídica", En: La Posesión, tomo 2, Editorial Espasa Calpe.

25 La posesión ilegitima se divide entre la de buena fe y mala fe (artículo 906 del Código Civil)

- Buena fe, cuando existe desconocimiento de la falta de un derecho o un título invalido, sea por error de hecho o de derecho.

- Mala fe, cuando se conoce que no existe derecho.

Mejorada Chauca, Martín, La Posesión en el Código Civil Peruano, Derecho y Sociedad, $40^{\circ} \mathrm{Ed}$.

27 Jiménez Vargas-Machuca, Roxana, "La posesión. Alcances y defensa", De Belaunde López De Romaña, Javier; Bullard González, Alfredo; Pizzaro Adranguren, Luis; y Soto Coaguila, Carlos; Alberto, En: "Homenaje a Jorge Avendaño", PUCP - Fondo Editorial, Año 2004. 
especial cuando estos entran en conflicto. Como comentáramos anteriormente, la defensa posesoria (judicial y extrajudicial) es básicamente rápida y efectiva pero en ningún caso definitiva, en cambio, la defensa de la propiedad es normalmente más lenta pero definitiva ${ }^{28}$. Por ello, salvo circunstancias especiales ${ }^{29}$, el conflicto entre posesión y propiedad, lo termina ganando la propiedad.

\section{Defensa posesoria}

Citando a Romero Romaña ${ }^{30}$, "el poseedor tiene derechos como la conservación de la posesión y la protección posesoria, o sea el de ejercitar las acciones necesarias para defender la posesión, estos mecanismos de defensa posesoria operan sin necesidad de comprobarse la legitimidad de su posesión". Como señaláramos anteriormente, el Código Civil regula dos formas de ejercer la defensa posesoria, la extrajudicial y la judicial. Pasaremos a realizar una breve descripción de estos mecanismos.

La defensa judicial de la posesión se ejerce a través de los interdictos de retener y recobrar. El interdicto de retener protege al poseedor respecto a los actos perturbatorios que pudieran afectarle, estos actos perturbatorios pueden consistir en meras molestias a la forma en que viene poseyendo el bien o a intentos, no exitosos, de despojarlo de dicha posesión, su objeto es que cesen los actos perturbatorios. El interdicto de recobrar por su parte, protege al poseedor ya despojado y le permite recuperar la posesión del bien.

El poseedor perturbado o despojado tiene hasta un año (contado desde el primer acto de perturbación ${ }^{31}$ o desde el despojo) para presentar su demanda. Los interdictos se

28 En el caso de un conflicto entre el poseedor y el propietario del bien, el propietario cuenta con mecanismos legales para recuperar su bien (acciones posesorias, acción reivindicatoria). Sin embargo, cuando recupere su bien sin seguir las vías legales correspondientes, podría sufrir los efectos de la defensa posesoria (judicial o extrajudicial) y perder el bien nuevamente. En este último caso, el propietario podría reiniciar su acción por la vía legal (por ejemplo con una acción reivindicatoria) y recuperar finalmente el bien de su propiedad).

29 En el caso de la prescripción, donde un poseedor ilegitimo adquiere propiedad, en palabras de Alfredo Bullard: "La negligencia de un propietario llega a niveles tales que permite a un usurpador poseer sus bienes por periodos tan largos sabiendo que ello puede implicar la pérdida del bien." En consecuencia, ¿la ley castiga al propietario por su negligencia? ¿Se premia al poseedor ilegitimo.

El mismo autor explica luego que, lo que se busca es probar quien es propietario, es decir, la prescripción adquisitiva se convierte en una prueba de propiedad.

Romero Romaña, Eleodoro; Derecho Civil - Los Derechos Reales, Editorial P.T.C.M., 1947 pg. 82.

31 Existe cierto debate respecto a desde cuándo se debe contar el plazo en el caso de perturbaciones continuas. Una posición indica que tratándose actos perturbatorios continuos, cada nuevo acto renueva el plazo para interponer el interdicto, al respecto

FORSETI

Número 2

2014 
Civil.

tramitan en la vía sumarísima, lo que supone un trámite más expeditivo que la del proceso de conocimiento. De acuerdo con lo establecido en el artículo 921 del Código Civil, los interdictos proceden solo respecto a bienes inmuebles y muebles inscritos, no proceden respecto a bienes de uso público ${ }^{32}$.

Si bien los interdictos constituyen una vía preferencial de defensa de la posesión, tiene dos inconvenientes saltantes, en primer lugar, no protegen la posesión de todos los bienes, se excluyen los bienes muebles no inscritos, en segundo lugar, a pesar de tratarse de una vía procedimental más corta, no deja de ser un proceso judicial que en cualquier caso es costoso y largo.

Por su parte, la defensa extrajudicial es una vía más directa y rápida para conservar la posesión o recuperarla. El artículo 920, autoriza la defensa extrajudicial de la posesión en el supuesto de que un poseedor soporta un despojo o un intento de despojo. En estos casos, se autoriza el uso de la fuerza por el poseedor, siempre que actúe de forma inmediata y proporcional ${ }^{33}$. Como hemos señalado anteriormente, estamos ante un supuesto de autocomposición o "justicia de propia mano" que, por excepción, admite incluso el uso de la fuerza.

La función de la defensa posesoria es repeler la fuerza con la fuerza. Esta norma ha sido objeto de una reciente modificación con la promulgación de la Ley $N^{\circ} 30230$, cuyo artículo que modifica el artículo 920 del Código Civil es materia de discusión en el presente trabajo y será desarrollado en su última parte.

Finalmente, una vez concluida, y no aprovechada, la oportunidad de una protección directa e inmediata de la posesión, ya no procede recuperar directamente la posesión y solo queda utilizar la vía judicial como medio de defensa de la posesión.

\section{Defensa extrajudicial de la posesión}

Como hemos explicado anteriormente, la defensa extrajudicial de la posesión, regulada por el artículo 920 del Código Civil, constituye uno de los supuestos de autotutela admitido por nuestro ordenamiento. En ese sentido, se trata de un supuesto excepcional de solución de conflictos que, debe estar supeditado a que los actos

ver; Avendaño A., Francisco. "Los Interdictos". Scribas, Revista de Derecho. Año I, N², P. 66. En nuestra opinión, por el contrario, en el caso de actos perturbatorios continuos, debe contarse el plazo desde el primer acto perturbatorio, esto en tanto estamos ante un plazo que extingue la acción debido a la negligencia del potencial demandante y en el supuesto el poseedor viene soportando y aceptando la perturbación desde el primer momento.

Artículo 599 del Código Procesal Civil.

33 Los alcances de una defensa inmediata y proporcional de la posesión serán desarrollados en la siguiente parte de este trabajo. 
destinados a la conservación o recuperación de la posesión se realicen de forma inmediata y proporcional.

Antes de analizar el nuevo texto del artículo 920, revisaremos los alcances de su texto original y revisaremos sus efectos.

Hasta su modificación, el artículo 920 admitía que el poseedor, repela la fuerza que se emplee contra él y que recobre el bien del que ha sido despojado de forma directa, por lo que estamos ante uno de los supuestos de autotutela autorizada por nuestro ordenamiento.

Respecto a los alcances del texto derogado surgían las siguientes preguntas que trataremos de absolver.

\section{1 ¿Puede el poseedor despojado acudir al auxilio de la fuerza pública para ejercer la defensa posesoria extrajudicial?}

Podría parecer obvio que, ante la flagrante violación de un derecho, cualquier ciudadano puede acudir a la fuerza pública por su protección, sin embargo, no necesariamente esta protección se enmarca dentro de los alcances de la defensa extrajudicial de la posesión, sino más bien en la protección general que la fuerza pública de brindar frente a la inminente violación de un derecho y la flagrancia en la comisión de un delito. Un ejemplo podría servir para aclarar este tema, imaginemos que en la calle una persona es despojada de su reloj por un ladrón desarmado y de mínima peligrosidad, evidentemente, el despojado puede ejercer la defensa directa de la posesión y eventualmente para ello no necesite de la intervención policial pues tiene la fortaleza física para reducir al ladrón, sin embargo, si un policía ve la situación, debe intervenir (incluso sin la solicitud del agraviado) al estar ante la flagrante comisión de un delito. En este caso, el policía no estaría actuando en razón del artículo 920 del Código Civil, sino en ejercicio de sus funciones propias.

Por otro lado, el artículo 920 es un supuesto de autotutela que admite la defensa de la posesión de manera directa, sin embargo, en algunas ocasiones las características del despojo impiden que sea materialmente posible ejercer este mecanismo sin el auxilio de la fuerza pública. Pensemos, por ejemplo, en un terreno de importantes dimensiones en los límites de una propiedad que es objeto de una invasión por parte de algunos cientos de personas. En ese caso, va a ser materialmente imposible que el poseedor pueda defender su posesión de manera directa sin el apoyo de la fuerza pública. Son casos como los del ejemplo los que avalan el apoyo de la fuerza pública para el ejercicio de la defensa posesoria extrajudicial.

Al respecto, Jiménez Vargas Machuca, señala:

"Es conveniente incidir sobre el presupuesto de que debe hacerlo sin intervalo de tiempo, como establece la norma, ya que de otro modo el 
camino solo sería vía la acción judicial correspondiente, como un interdicto. Por ello, resulta indispensable que entre el ataque y la reacción exista una "verdadera unidad de tiempo", pues la razón de ser del principio de defensa privada extrajudicial radica en la necesidad de ejercitar una acción inmediata allí donde falta la autoridad, y aquí es menester resalta que es indispensable que se carezca de intervención de autoridad competente para que proceda la acción por mano propia. ${ }^{34 \prime \prime}$ (Énfasis agregado).

La autora citada es de la opinión que la defensa extrajudicial de la posesión debe realizarse sin intervención de autoridad competente. Al respecto, cabe reflexionar sobre los alcances de la autotutela y distinguir entre la decisión de defender directamente la posesión, que implica no acudir a la autoridad para que ésta resuelva el conflicto, y la propia acción de defensa extrajudicial, donde se plantea si es válido acudir al apoyo de la fuerza pública.

En nuestra opinión, la naturaleza de la defensa extrajudicial de la posesión no admite el uso de la fuerza pública para su ejecución. Como ya hemos señalado a lo largo de este trabajo, la defensa extrajudicial es una alternativa excepcional de solución de conflictos, que admite el uso de la fuerza y debe interpretarse con restricción, lo contrario sería admitir el uso de la fuerza (privada o pública) de forma indiscriminada y peligrosa, poniendo en peligro el propio estado de derecho. Debe tenerse en cuenta que el uso de la fuerza pública, se debe dar en el marco de un mandato judicial o en los casos de un delito flagrante. Admitir el uso de la fuerza pública para la defensa extrajudicial de la posesión implicaría que el poseedor despojado estaría reemplazando al juez y eso no es admisible, en todo caso, el texto del artículo $920^{\circ}$ original, no lo admitía expresamente. Caso distinto es el de la intervención policial ante un flagrante delito, en este supuesto, se justifica la intervención de la fuerza pública, pero esta no se produciría en el marco de la defensa extrajudicial de la posesión sino en el ejercicio de sus propias funciones.

\section{2 ¿Qué debe entenderse por actuar sin intervalo de tiempo?}

El artículo 920 modificado exigía que la defensa extrajudicial de la posesión, para ser legítima, debía realizarse, "sin intervalo de tiempo". Con esto se busca que esta situación excepcional, donde se admite la autotutela, tenga un halo temporal breve y que transcurrido este tiempo, el conflicto posesorio sea resuelto a nivel judicial.

34 Jiménez Vargas Machuca, Roxana, "La Posesión. Alcances Y Defensas" En De Belaunde López De Romaña, Javier; Bullard González, Alfredo; Pizarro Adranguren, Luis; y Soto Coaguila, Carlos Alberto; En "Homenaje A Jorge Avendaño", PUCP - Fondo Editorial, Año 2004 P. 735. 
Sobre el particular, se plantea la duda respecto a si la inmediatez que la norma exigía debía considerarse desde la ocurrencia del despojo o desde que el poseedor despojado toma conocimiento de dicha situación.

Al respecto, el entender que "sin intervalo de tiempo" debía contarse desde que se producía el despojo, restringía el uso de la defensa extrajudicial y, con ello, la gran mayoría de situaciones se debían resolver a nivel judicial. Además, se generaba el problema de que si el poseedor no se encontraba presente en el momento del despojo, no se produciría la posibilidad de ejercer la defensa extrajudicial de la posesión. Se producirían, en el marco de esta interpretación, casos en que el despojado se ausente por pequeños lapsos de tiempo y que, no obstante, tendría que acudir al poder judicial para recuperar la posesión del bien.

Considerar que "sin intervalo de tiempo" debía contarse desde el conocimiento efectivo del poseedor despojado (que es la posición que expresamente contiene el nuevo textote la norma) generaba por su parte un marco de acción mucho más amplio para la defensa extrajudicial de la posesión. Sin embargo, creemos que una interpretación así de amplia puede generar problemas graves que trataremos de graficar en el siguiente ejemplo.

Por motivos laborales, el propietario y poseedor de una casa se ve obligado a salir del país durante tres años, no deja a nadie a cargo del inmueble y realiza los pagos del impuesto predial y arbitrios municipales a través de Internet. Apenas transcurridos unos días del viaje del propietario, una familia aprovecha para entrar a habitar la casa, lo que hacen sin mayor oposición. El propietario regresa de su viaje y encuentra su casa ocupada.

En este caso se admitiría el uso de la defensa extrajudicial de la posesión pues el despojado recién ha tomado conocimiento del despojo. En nuestra opinión, la aplicación de un criterio tan flexible genera, en casos así, el problema de que la opción de la defensa extrajudicial de la posesión se mantenga vigente en un periodo de tiempo tan largo que es contradictorio con el principio de inmediatez de la misma y que es congruente con el carácter excepcional de la institución. Además, debe tenerse en cuenta que, transcurrido tanto tiempo, los miembros de la familia que ocupan la casa tiene la condición de poseedores y también se encuentran legitimados para ejercer la defensa extrajudicial de la posesión ${ }^{35}$. Al respecto, es obvio que la posibilidad de que las dos partes enfrentadas en el conflicto puedan hacer justicia por su propia mano es contraria a la institución de la defensa extrajudicial de la posesión y el estado de derecho.

Como alternativa, proponemos que, si bien el plazo de posesión se debe contar desde la toma de conocimiento del despojado, el derecho a ejercer la defensa extrajudicial de

${ }^{35}$ La norma no se pronuncia sobre esta situación, ni restringe está posibilidad. 
Civil.

la posesión debe extinguirse en tanto el despojante se consolide como nuevo poseedor del bien, lo que deberá determinarse de acuerdo al tipo de bien y las circunstancias. En ese sentido, en el ejemplo planteado, si bien el despojado recién toma conocimiento del despojo, no podrá ejercer la defensa posesoria contra quienes tienen una posesión estable. En cambio, en los casos en que, habiendo transcurrido un tiempo desde el despojo, el despojante no ha ejercido un uso estable, público y razonable que le permita ser beneficiario de la protección posesoria ${ }^{36}$, el despojado podrá recuperar su posesión de manera directa.

El proyecto 3627-2013-PE, que ha sido aprobado en la Ley $\mathrm{N}^{\circ} 30230$, buscaba modificar el artículo $920^{\circ}$ del Código Civil a efectos de establecer que:

1. La acción de la defensa posesoria puede ejercerse en un plazo de 15 días.

2. El propietario de un inmueble que no tenga edificación o esté en dicho proceso posee directamente $y$, en ese sentido, puede invocar tal acción si es desposeído por un poseedor precario; $y$,

3. No procede la defensa posesoria si el poseedor precario ha usufructuado el bien como propietario por lo menos 10 años.

Al respecto, los beneficios de la modificación del artículo 920 del Código Civil que la exposición de motivos del proyecto señalaba, son los siguientes:

1. Dar viabilidad a la defensa posesoria otorgando un plazo real que pueda hacer efectivo la misma. El plazo de las 24 horas que hoy se aplica es irreal y anula el mecanismo de defensa dando ventajas a los invasores.

2. Dar un mecanismo de defensa al propietario que posee un terreno o un inmueble en construcción. La presunción permite defenderse de los invasores y no genera daños, ya que aplica en inmuebles vacíos o en construcción.

3. Reconoce que no proceda la defensa posesoria si el poseedor directo ha usufructuado el bien como propietario por 10 años. Ello da seguridad jurídica y reconoce el aspecto social del poseedor pacífico como propietario.

Antes de analizar cada uno de los extremos modificados, conviene hacer un cuadro comparativo de ambas normas.

En tanto para ser poseedor es necesario comportarse como razonablemente lo haría el propietario, no puede asumirse que la condición de poseedor se adquiere de inmediato, por el contrario, es necesario un comportamiento continuo para acceder a la condición de poseedor. 


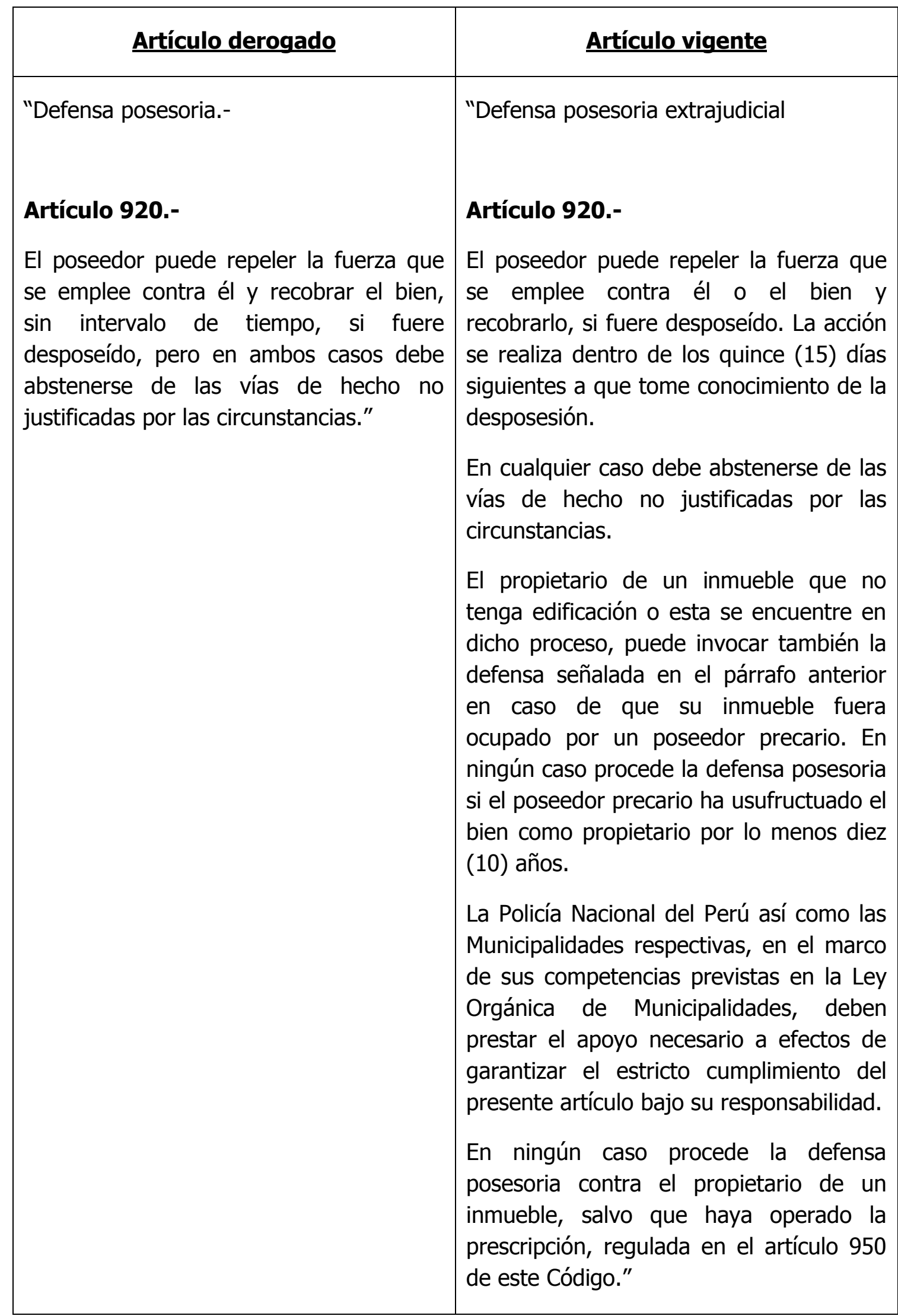


¿Ojo por ojo, diente por diente?:

Análisis de la modificación del artículo 920 del Código

Civil.

Seguidamente, analizaremos las modificaciones realizadas al artículo 920 del Código Civil.

\subsection{Se puede repeler la fuerza que se emplee contra el bien.-}

Esta es una novedad del nuevo texto, no queda clara la intención del legislador con esto pero sus efectos son bastante importantes. En especial, parece que con el cambio se termina extendiendo la defensa extrajudicial de la posesión, que tradicionalmente se ha restringido a la defensa frente a despojos ${ }^{37}$, a la defensa frente a perturbaciones ${ }^{38}$. Esto en la medida que el uso de la fuerza contra el bien, dirigida a perpetrar un despojo, ya daba lugar a la defensa posesoria extrajudicial, en cambio, la defensa extrajudicial de la posesión frente a perturbaciones ${ }^{39}$ sería una novedad que ampliaría el ámbito de la defensa extrajudicial, lo que nos parece innecesario y hasta peligroso.

\subsection{Se aclara que el plazo para la defensa extrajudicial de la posesión se contabiliza desde el conocimiento de la desposesión.-}

Ya hemos opinado que la aplicación del criterio del conocimiento de manera irrestricta es excesivo, peligroso y debería compatibilizarse con la condición de poseedores de los despojantes. Es más, el nuevo texto al indicar que "En ningún caso procede la defensa posesoria si el poseedor precario ha usufructuado el bien como propietario por lo menos diez (10) años. "Daría entender que transcurridos 8 o 9 años desde el despojo, si podría ejercerse la defensa extrajudicial de la posesión, lo que es un despropósito.

Adicionalmente, debe tenerse en cuenta que la prueba respecto a la fecha de conocimiento puede ser muy complicada y, en la práctica, puede estar referida a la mera declaración del ex poseedor.

\subsection{Se otorga un plazo de 15 días desde la toma conocimiento de la desposesión.-}

Sobre este punto conviene apreciar, que la modificación establece un plazo de 15 días para ejercer la defensa posesoria, a diferencia de la inmediatez a la que hacía referencia el texto original del artículo $920^{\circ}$.

El tema del establecimiento de un plazo guarda estrecha relación con dos temas que se discutían mientras estuvo vigente el texto original del artículo $920^{\circ}$, la exigencia de inmediatez y la intervención policial. Al respecto, se cuestionaba la exigencia de la

\footnotetext{
37 Que a nivel judicial se tramitan como un interdicto de recobrar.

38 Que a nivel judicial se tramitan como interdictos de retener.

39 Que se manifestarían en la afectación al bien.
} 
inmediatez en especial cuando se interpretaba que debía considerarse desde la ocurrencia del despojo, lo que por lo demás ya ha sido modificado por el texto vigente.

Respecto a la intervención de la policía en apoyo de los poseedores despojados, como hemos señalado anteriormente, al no haber una autorización expresa para su participación ni, por lo tanto, un procedimiento establecido, se recurría a la práctica policial. En ese sentido, el protocolo policial establece que cabe intervención policial frente a un delito flagrante dentro de las 24 horas de ocurrido el hecho ${ }^{40}$. A partir de ello, se pasó a interpretar, de manera errónea, que el plazo de la inmediatez se restringía a esas 24 horas.

Como consecuencia, el plazo de 15 días (contados además desde el conocimiento) viene a ser una suerte de ampliación del plazo anterior y busca facilitar el apoyo de la fuerza pública en la defensa extrajudicial de la posesión, que por lo demás ha quedado también consagrada. Esto nos parece por demás inadecuado, rompe la lógica de la defensa extrajudicial de la posesión y abre la puerta al uso indiscriminado de la fuerza, sin contar con un mandato judicial que así lo justifique.

Al respecto, es pertinente citar a Jiménez Vargas Machuca, que señala lo siguiente:

\begin{abstract}
"Así, en determinados supuestos, quien ha sido despojado de su posesión, puede recurrir a las vías de hecho, es decir, al empleo de la fuerza, por medio de la defensa extrajudicial o autodefensa, ya que de lo contrario se consumaría una injusticia. (...). En tal virtud, "quien es despojado de la posesión (ya sea titular o no titular), puede, mientras lo haga inmediatamente, esto es, mientras dure la ofensa, quitar legítimamente, él mismo, al usurpador de la cosa, sin que con ella incurra en el delito de "tomarse la justicia por su mano" ${ }^{\prime 41}$. (Énfasis agregado)
\end{abstract}

Claramente, lo regulado en el nuevo texto no persigue el mismo objetivo que este particular tipo de protección. En efecto, establecer un plazo de 15 días contados desde el conocimiento del despojo puede resultar un mecanismo de defensa desproporcional a la conducta que realiza el invasor debido a que un plazo de más de dos semanas permite al despojado utilizar medios de "defensa" mucho más elaborados para ejercer la autotutela.

\title{
5.6 El propietario de un inmueble sin edificación puede usar la defensa posesoria extrajudicial contra un poseedor precario.-
}

\footnotetext{
40 Se debe tener en cuenta que este no es un plazo para la defensa de la posesión.

41 Jimenez Vargas Machuca, Roxana; De Belaunde López De Romaña, Javier; Bullard González, Alfredo; Pizzaro Adranguren, Luis; y Soto Coaguila, Carlos Alberto, En: "Homenaje a Jorge Avendaño", PUCP - Fondo Editorial, Año 2004736.
} 
Civil.

Sobre este punto es evidente que el legislador confunde la defensa posesoria con la protección de la propiedad. La posesión, dado su carácter de hecho, justifica una protección rápida y eficaz, aunque esta no sea en ningún caso definitiva. En el caso de la propiedad, está detrás una titularidad que, como tal, puede ser cuestionada o disputada, por eso los conflictos relativos a la propiedad se ven en procesos de conocimiento donde se busca tener un espacio de discusión más amplio. Con el nuevo texto, indirectamente se admite que el propietario no poseedor pueda recurrir a la defensa extrajudicial para recuperar su bien, obviando la vía del proceso de desalojo.

Esta disposición nos sugiere dos comentarios, en primer lugar, no deberíamos utilizar la institución de la defensa extrajudicial de la posesión, que debe ser excepcional, para resolver otros casos, que pueden ser atendibles, pero que no son parte del supuesto. En segundo lugar, la ampliación de los supuestos de autotutela constituye una medida de gran relevancia en nuestro ordenamiento y ameritaría un debate más transparente y público.

\subsection{La Policía Nacional y las Municipalidades podrán auxiliar al agraviado despojado.-}

El nuevo texto de la norma consagra la participación de la Policía Nacional y las Municipalidades ${ }^{42}$ para colaborar con el despojado en la recuperación de su posesión. Al respecto ya nos hemos pronunciado respecto a la inconveniencia de esta medida.

En la práctica, se movilizará a la fuerza pública y se alterará una situación de hecho, a partir de un pedido del supuesto agraviado, ${ }^{43}$ sin que esto haya sido avalado por ninguna autoridad o tercero independiente.

Reiteramos nuestra opinión en el sentido que esta disposición es antitécnica, pues contraviene la naturaleza de la defensa extrajudicial de la posesión y sus fines, y conlleva el riesgo de que este apoyo estatal sea mal utilizado y afecte la convivencia social.

\subsection{No procede la defensa posesoria contra el propietario de un inmueble, salvo que haya operado la prescripción, regulada en el artículo 950 de este Código.-}

Nuevamente, el legislador confunde los alcances de la protección de la posesión y la propiedad. Es más, en esta oportunidad el legislador ha disminuido la protección posesoria.

\footnotetext{
42 Entendemos que a través del serenazgo.

43 La posesión del supuesto despojante.
} 
De acuerdo a nuestro ordenamiento, la protección posesoria es independiente de la legitimidad del poseedor, incluso el poseedor de mala fe es protegido por la ley con la prescripción adquisitiva, las mejoras, los interdictos y hasta esta reforma con la defensa posesoria extrajudicial.

En efecto, en muchos casos, los conflictos posesorios se producen entre el poseedor y el legítimo propietario. Es el caso, por ejemplo, del propietario de un bien arrendado que decide recuperar de forma directa (y hasta violenta) el inmueble de su propiedad que se encuentra en posesión de un inquilino que no cumple con sus pagos o al que se le ha cumplido el plazo del arrendamiento y no ha cumplido con devolver el bien.

En ese caso, la defensa extrajudicial de la posesión servía para que el poseedor pueda defender su posesión contra este actuar indebido del propietario, dado que este último pretende recuperar su bien de una forma que nuestro ordenamiento jurídico rechaza. Si bien, podría parecer injusto que el poseedor sea protegido frente al legítimo propietario, sucede que en este caso se sanciona al propietario por haber usado "vías de hecho" para hacer valer su derecho y se le obliga a seguir las vías correctas. A partir de la modificación, los poseedores ven disminuida su protección y tendrán que recurrir a la protección de los interdictos.

Sobre este aspecto, creemos que este tipo de modificaciones desvirtúan la verdadera finalidad por la que fue creada la defensa posesoria extrajudicial ya que extienden los requisitos hacia supuestos que alejan la cualidad excepcional de esta figura jurídica. Ahora bien, con esto no estamos amparando la conducta reprochable del invasor, sino que se tiene que hacer una verdadera distribución de los conflictos que tienen que ser analizados en las instancias correspondientes de acuerdo a las particularidades de caso. Los nuevos supuestos que la norma estipula para ejercer la defensa posesoria resultan tan desproporcionados que el mecanismo pierde efectividad puesto que si bien empezó como una excepción haciendo muy restrictivo el supuesto de hecho, ahora trata de forzar la figura y la posibilidad de que se generen más conflictos y peligros para la sociedad.

En conclusión, consideramos que la modificación del artículo 920 del Código Civil, a pesar de su intención de facilitar la protección de poseedores y propietarios, no ha sido una reforma adecuada pues ha excedido los que deberían ser los alcances de la defensa extrajudicial de la posesión y puede conllevar mayores conflictos y problemas que los que ha querido resolver. Esto no quiere decir que rechazamos cualquier propuesta que mejore las condiciones de la defensa extrajudicial de la posesión. Sin embargo, creemos que hubiese sido preferible hacer algunos ajustes en la norma y paralelamente mejorar los mecanismos judiciales de defensa de la posesión e incluso evaluar el establecimiento de algunos mecanismos administrativos para facilitar este tipo de defensa, que reiteramos, debe ser excepcional. Creemos que, en el contexto en 
¿Ojo por ojo, diente por diente?:

Análisis de la modificación del artículo 920 del Código

Civil.

el que vivimos, la Ley del Talión tiene que ser el último recurso que debe emplearse si es que queremos ver un avance progresivo y significativo en nuestra sociedad. 